\title{
FORMACÃO TÉCNICA E EMPREGABILIDADE EM PROGRAMAS SOCIAIS: A EXPERIÉNCIA DO PROGRAMA BOLSA FAMÍLIA E DO PRONATEC EM UMA CIDADE DA FRONTEIRA BRASIL-URUGUAI
}

\author{
GUILHERME DORNELAS CAMARA - (https://orcid.org/0000-0001-5021-9535) \\ Universidade Federal do Rio Grande do Sul, Porto Alegre, RS, Brasil
}

RESUMO: O objetivo deste trabalho é analisar a repercussão do Programa Nacional de Acesso ao Ensino Técnico e ao Emprego (PRONATEC) para a inserção e qualificação profissional. Nos debates acadêmicos, técnicos e do senso comum sobre a sua efetividade para o fim da pobreza, muitas vezes se questiona sua influência sobre a estabilidade do trabalhador no mercado de trabalho. Contudo, poucos estudos têm se dedicado a verificar junto aos próprios beneficiários a relevância do PRONATEC para a inserção profissional, caminho considerado sustentável para o combate à situação de vulnerabilidade das famílias beneficiárias. Propondo-se a essa análise, o trabalho parte de dados coletados em entrevistas com beneficiários do PRONATEC e do PBF (Programa Bolsa Família) em uma cidade da fronteira do Brasil com o Uruguai. É abordada a importância econômica dos programas sociais para as famílias frente às dificuldades do mercado de trabalho local.

Palavras-chave: PRONATEC; Educação profissionalizante; Empregabilidade; Programas sociais.

TECHNICAL EDUCATION AND EMPLOYABILITY IN SOCIAL PROGRAMS: THE EXPERIENCE OF BOLSA FAMÍLIA PROGRAM AND PRONATEC IN A CITY IN THE BRAZIL-URUGUAY BORDER

Abstract: This paper aims to analyze the repercussions of the National Program for Accessing Technical Education and Employment (PRONATEC) for professional insertion and qualification. In academic debate, common sense and technical discussion about its efectiveness to end poverty, its influence in the workers' stability in the labor market is often questioned. The path of professional insertion is generally seen as sustainable to fight the vulnerability of the families. However, few studies have been dedicated to verify the view of the beneficiaries themselves. Proposing such analysis, this paper brings data collected from interviews with beneficiaries of PRONATEC and Bolsa Familia Program (PBF) in a

\footnotetext{
* Doutor em Administração. Professor Adjunto no Departamento de Ciências Administrativas da Universidade Federal do Rio Grande do Sul. Membro do Grupo de Pesquisa Organização e Práxis Libertadora. Correio eletrônico: < guilherme.dornelas@ufrgs.br.>
} 
city in the Brazil-Uruguay border. The programs' economic importance to the families is approached facing the difficulties of the local labor market.

Keywords: PRONATEC; Professional education; Employability; Social programs.

\section{INTRODUĈ̣̃O}

Em outubro de 2011, o Governo Federal lançou o Programa Nacional de Acesso ao Ensino Técnico e Emprego (PRONATEC), vinculado ao Ministério da Educação, que previa "uma série de subprogramas, projetos e ações de assistência técnica e financeira" com o "objetivo principal de expandir, interiorizar e democratizar a oferta de cursos de Educação Profissional e Técnica (EPT)" (BRASIL, 2012b). Esse Programa propunha-se à inclusão produtiva dos beneficiários do Programa Bolsa Família (PBF), criado em 2004, e constitui uma das frentes de ação do Plano Brasil Sem Miséria. Por isso, o esclarecimento da relação entre os Programas é crucial para a compreensão do contexto em que se dá o PRONATEC.

Pioneiro dos programas sociais dos governos Lula e Dilma, o Programa Bolsa Família (PBF) foi instituído pelo Governo Federal através da Lei n. ${ }^{\circ} 10.836$ de 2004, como a principal política social para o combate à pobreza no país. O PBF tem como objetivo superar a condição de pobreza em que parte do povo brasileiro vive, transferindo renda com condicionalidades na educação e na saúde. O PBF parte de definições de pobreza e pobreza extrema desenvolvidas por organismos multilaterais como o Banco Mundial e o Programa das Nações Unidas para o Desenvolvimento (PNUD). Em consonância com essas definições, as recomendações desses organismos e de autores como Amartya Sen, John Rawls e Milton Friedman são incorporadas ao desenho do combate à pobreza articulado em torno desse Programa.

À época, o Governo Federal definira que a pobreza extrema, também chamada de miséria, correspondia à condição de vida abaixo da Linha de Pobreza Extrema, fixada na renda mensal per capita de $\mathrm{R} \$$ 70,00, o que equivale a aproximadamente 1 dólar PPC por dia. A linha de pobreza, por sua vez, ficou estabelecida em uma renda familiar de $R$ \$ 140,00 mensais per capita. Essa definição da pobreza permitiu a focalização das ações do PBF em um público-alvo específico. Ainda hoje, podem pleitear a inscrição no Programa as famílias que pertencem a essa faixa de renda e possuam crianças em idade escolar, filhos portadores de deficiências físicas e mulheres grávidas.

Todas as famílias interessadas em participar do PBF devem estar inscritas no CadÚnico, um banco de dados criado para centralizar 
e unificar os cadastros dos beneficiários do Governo Federal. As famílias extremamente pobres recebem um Benefício Básico no valor de $\mathrm{R} \$ 85,00$ mensais, que é pago mesmo que elas não tenham crianças, adolescentes ou jovens. Esse valor pode ser complementado por um Benefício Variável (BV) de R \$39,00 mensais para cada filho, até o limite de cinco crianças e adolescentes até 15 anos. Para famílias com adolescentes de 16 e 17 anos, o Governo Federal paga o Benefício Variável Vinculado ao Adolescente (BVJ), de R \$46,00, até o limite de dois jovens. Com base nesses parâmetros, o valor percebido por famílias extremamente pobres pode variar de $\mathrm{R} \$ 85,00$ a $\mathrm{R} \$ 372,00$.

Para receber os valores pagos mensalmente, as famílias beneficiárias devem manter as crianças e os jovens em idade escolar frequentes às aulas; os menores devem cumprir com o calendário de vacinação e as gestantes devem fazer os exames e consultas de prénatal. As informações sobre o cumprimento das condicionalidades são fornecidas pelas das Secretarias Municipais e Estaduais de Saúde e de Educação para o Governo Federal.

O PBF é financiado pelo Fundo Nacional de Assistência Social, a partir de dotação específica no Orçamento da União e, de acordo com a Lei 10.836, o Poder Executivo deve compatibilizar a quantidade de beneficiários do Programa com as dotações orçamentárias existentes. Em 2011, o Programa transferiu R\$ 17.283.104.720,00 para cerca de 12,8 milhões de famílias (BRASIL, 2012a), Em 2016, $\mathrm{R} \$ 2$ 28.506.168.795,00 foram distribuído para, aproximadamente, 13,9 milhões de famílias (BRASIL, 2017). Além desse montante, uma parte dos recursos é destinada aos estados e municípios para apoio financeiro às ações de gestão e execução descentralizada do Programa (BRASIL, 2004). A Lei 10.836 determina que, preferencialmente, os benefícios sejam pagos às mulheres, responsáveis pela inclusão das famílias no CADUN e pelo cumprimento das condicionalidades.

A partir de 2011, a focalização do PBF na população extremamente pobre, isto é, com renda per capita inferior a 70 reais mensais, foi fortalecida com o lançamento do Programa Brasil Sem Miséria, complementar ao Bolsa Família. Com esse novo Programa, o Governo visa alcançar de modo mais efetivo a população abaixo da linha de pobreza extrema (miséria), articulando a transferência de renda e o cumprimento de condicionalidades ao acesso a serviços públicos, como saúde e educação.

Um dos objetivos do Brasil Sem Miséria de aumentar o acesso das famílias extremamente pobres aos serviços públicos é realizado, mormente, com as visitas das Equipes de Saúde da Família nos domicílios, nas escolas e nos Centros de Referência em Assistência 
Social (CRAS) dos municípios. Nesse sentido, a relação entre a transferência de renda e o acesso a esses serviços para os beneficiários do PBF é mediada pelo cumprimento das condicionalidades.

No âmbito dos Estados e das Municipalidades, os Governos e Prefeituras têm firmado convênios para oferecer cursos profissionalizantes para a população, privilegiando a inscrição de membros de famílias beneficiárias do PBF.

O Rio Grande do Sul foi um dos primeiros estados a pactuar com o Governo Federal o Plano Brasil Sem Miséria e o PRONATEC, um Programa Estadual de Combate à Pobreza, o RS Mais Igual. Neste Programa, o Governo do Estado proporciona aos beneficiários do PBF matriculados no Ensino Médio, Educação de Jovens e Adultos ou cursos de qualificação profissional até $\mathrm{R} \$ 100,00$ a mais no Benefício Básico do PBF. Nesse estado, um dos principais conveniados para a oferta de cursos do PRONATEC são as agências do Serviço Nacional de Aprendizagem Comercial (SENAC), pertencentes ao Sistema S ${ }^{1}$.

Nesse trabalho, analisamos o impacto oferecido pelos Programas Bolsa Família e PRONATEC para a inserção profissional das famílias beneficiárias do município gaúcho de Sant'Ana do Livramento, localizado na fronteira com o Uruguai. Os dados foram coletados com trabalhadores da Prefeitura Municipal que desenvolvem atividades relacionadas ao PBF, com representante do SENAC do Município que atuavam no âmbito dos cursos PRONATEC e beneficiários do Programa Bolsa Família. Trata-se de uma pesquisa qualitativa, exploratória, que analisa os dados interpretativamente ao referencial teórico consolidado.

De modo a realizar essa análise, o artigo está organizado da seguinte maneira: na próxima seção é apresentada uma breve revisão teórica sobre os Programas Bolsa Família e PRONATEC; na seguinte são apresentadas as principais referências para combater a pobreza e seu combate; subsequentemente são apresentados e discutidos os dados; por fim, são elaboradas algumas considerações, seguidas das referências adotadas no trabalho.

\section{BREVE REVISÃO TEÓRICA SOBRE OS PROGRAMA BOLSA FAMÍLIA E PRONATEC}

O Programa Bolsa Família (PBF) e o Plano Brasil Sem Miséria (BSM), como já dito, são Programas de Transferência Condicionada de Renda (PTCs) e acerca deles há um debate sobre sua universalidade e/ou focalização (COSTA, 2009; MEDEIROS e COUTO, 2009; NASSIF, 2012). Nas discussões de especialistas, têm-se reforçado 
que o conceito de pobreza que subjaz os Programas entende o seu caráter multidimensional e a falta de liberdades e oportunidades que o define (BRONZO, 2006; 2008).

Outro ponto relevante nos debates sobre o tema são as condicionalidades. De acordo com alguns autores, como Betto (2012), o PBF sofreu uma espécie de mutação liberal, pois ao invés de uma política transversal de caráter intersetorial (a exemplo do que parecia estar proposto no extinto Fome Zero), optou-se por uma política mais focalizada, centrada na oferta de benefícios monetários mediante 'contrapartida' dos beneficiários em responsabilização pela frequência escolar e pelo acompanhamento médico via Estratégia Saúde da Família e/ou pré-natal. Nesse bojo, as condicionalidades são tratadas como uma espécie de aposta nas políticas de transferência de renda, que seriam capazes de proporcionar aos beneficiários um futuro de "escolhas e oportunidades para viver uma vida tolerável" (PNUD, 1997, p. 15). Para alguns autores, as condicionalidades estariam vinculadas a um necessário aumento do capital humano ${ }^{2}$, pois "em longo prazo, a não acumulação do capital humano causado por escolaridade baixa e saúde precária é uma consequência negativa grave de trabalho infantil, representando uma oportunidade perdida para melhorar a produtividade e a capacidade de ganhos futuros da próxima geração" (GUERRA et al., 2011, p. 8). Outros autores vinculam as condicionalidades do PBF ao capital social ${ }^{3}$. Para Helal e Neves (2006, p. 6), ele é o determinante da pobreza e "o fato de um indivíduo pertencer a grupos ou associações, ou seja, a rede de relacionamentos (capital social) lá desenvolvida por este indivíduo passa a afetar positivamente a probabilidade dele escapar da pobreza".

No que diz respeito aos resultados que as condicionalidades geram para a superação da pobreza no largo prazo, Guerra et al. (2011, p. 12) afirmam que "não há nenhum controle do real rendimento escolar destas crianças. Este pode se apresentar como um ponto falho, uma vez que não há uma preocupação sistemática com o ensino e, sobretudo, a aprendizagem destas crianças, mas simplesmente, com a frequência escolar". Gluz e Moyano (2013) indicam que, também na Asignación Universal por Hijos, um PTC da Argentina bastante similar ao brasileiro, o governo federal exerce um controle das condicionalidades para o pagamento dos benefícios.

Sobre as origens dessa mutação liberal do PBF, pode-se recorrer a Cohn (2012, p. 21), quem explica que "associando-se o Fome Zero ao Bolsa Família, já o início do primeiro mandato do presidente Lula marca um governo que tem como prioridade, para além da estabilidade econômica, o combate à pobreza". A corrente 
do governo que propunha um PTC de grande abrangência venceu, em 2004, aqueles que defendiam a necessidade de uma reforma estrutural que combateria a miséria e a desigualdade social com o Fome Zero. Além da oferta de benefícios para famílias em regiões específicas do país, o Programa derrotado defendia a realização da reforma agrária, criação de cursos profissionalizantes, formação de cooperativas, restaurantes populares e bancos de alimentos, além de comitês gestores municipais e bancos populares.

Como Cohn (2012, p. 21) deixa claro, a intervenção dos organismos multilaterais na definição do Bolsa Família é inegável: "da perspectiva internacional, naquele momento a proposta de um grande programa de transferência condicionada de renda para os segmentos mais pobres da população, vinha ao encontro das posições das agências multilaterais". Para a autora, ainda há que se definir o significado do Programa Bolsa Família em termos do seu conteúdo social. "A questão é: sua configuração básica consiste meramente em constituir-se como um programa transversal de transferência de renda condicionada, com vistas ao alívio imediato da pobreza? Ou será um programa estruturante, voltado à construção da cidadania e da autonomia dos sujeitos sociais, seus beneficiários?" (COHN, 2012, p. 25).

No período de comemoração dos 10 anos dos governos de Lula e Dilma e do Bolsa Família, uma série de reportagens (O GLOBO, 2013; p. 12, 2013) divulgou o sucesso do Programa. Autores como Pochmann (2013) e Rego e Pinzani (2013) também publicaram pesquisas e análises elogiosos, reforçando a sua repercussão positiva para a cidadania, para o acesso aos serviços públicos e, principalmente, para "o tema da libertação das mulheres [sic], portanto da possibilidade de sua progressiva autonomização diante das muitas formas de domínio a que estão submetidas" (REGO e PINZANI, 2013, p. 19).

Estudos como os de Rego e Pinzani (2013, p. 178) destacam a tradição do trabalho infantil "seja ajudando nos afazeres da casa, seja em trabalhos fora de casa" e a importância das condicionalidades para evitar "o abandono da escola e, portanto, o analfabetismo e a impossibilidade de sair da miséria por meio da educação". A defesa recorrente de que o PBF liberta as mulheres, como afirmam Rego e Pinzani (2013) é feita também por Moreira et al. (2011, p. 13), que reconhecem, no entanto, que "o empoderamento econômico, avaliado como fundamental para a emancipação das mulheres, é alcançado apenas parcialmente". Nos termos desses autores, a libertação das mulheres tem o significado limitado à sua capacidade de poder adquirir bens de consumo sem ter que recorrer sempre aos homens. 
O PRONATEC (Programa Nacional de Acesso ao Ensino Técnico e ao Emprego), por sua vez, foi criado para ser um eixo do Brasil Sem Miséria, operando em paralelo ao PBF, de modo a oferecer vagas em cursos técnicos e profissionalizantes para os membros de famílias beneficiárias do PBF/BSM. Viccari e Martins (2014) chamam a atenção para a experiência do PRONATEC como política de qualificação profissional, fomentadora da inclusão social, como sendo um programa que envolveria a participação de diversos atores sociais, além de uma grande mobilização que visa alcançar a meta da qualificação profissional como forma de inclusão no mercado, seja de forma assalariada, ou através de formas alternativas de geração de renda. Silva (2016), por sua vez, reflete sobre como o PRONATEC insere-se na relação capital-trabalho e, concomitantemente, na trajetória da educação profissional no Brasil.

Uma das mais importantes questões apontadas pelas autoras é quanto ao movimento constante de diálogo como tentativa de buscar apreender a totalidade da realidade social deste público que deve ser qualificado para ser "incluído". Elas questionam a capacidade dos participantes do PRONATEC realizarem uma transformação nas condições em que vivem suas vidas. Segundo as autoras, há a incerteza quanto à efetiva participação da população mais pobre na política pública. Um dos limites que ainda barram o acesso e a inclusão, segundo Viccari e Martins (2014), é a baixa escolaridade que mesmo em uma modalidade FIC que busca a inclusão, ainda é mais baixa do que o mínimo necessário para acessar aos cursos.

Para Deitos, Lara e Zanardi (2015, p. 997) o PRONATEC

[...] é, sem dúvida, o alimentador teórico-ideológico e políticofuncional da articulação macroinstitucional-econômica e microeconômica-político institucional regional (estados/municípios; empresas/setores econômicos/trabalhadores) da parceria público-privada de desenvolvimento da política pública de educação profissional no país e nas unidades federativas e suas respectivas localidades municipais, além do fomento às instituições privadas, setores estes que hegemonizam os recursos e a direção teórica e funcional do processo e expansão da oferta e conteúdos requeridos, pela educação profissional, em cursos e treinamentos básicos e nos cursos de nível médio e técnico profissional, como também daqueles em nível tecnológico em instituições públicas e privadas no âmbito do ensino superior. Os fundamentos socioeconômicos e políticos, teórico-ideológicos e educacionais da política educacional, nessa direção, produzem vertiginoso discurso governamental, empresarial e funcional de que a ineficiência funcional e profissionalizante, de jovens e adultos trabalhadores, é mecanismo requerido pela dinâmica econômica, ao mesmo tempo em que leva os próprios trabalhadores a assumir (internalizar) como condição individualizada para a sua desqualificação/escolarização/qualificação, que acaba sendo reforçada e adotada como uma condição unilateral para o seu ingresso e permanência no processo produtivo (emprego e empregabilidade), e para a sua própria manutenção como força de trabalho, gerando internamente (nos 
indivíduos) as condições de aceitabilidade de expectativas sociais de desempenho escolar, qualificação e empregabilidade como condição unilateral à conquista de emprego no contexto econômico produtivo nacional.

Inserindo o PRONATEC no contexto da educação profissional brasileira, Silva (2016) enxerga a reprodução da relação capital-trabalho existente tradicionalmente no bojo da educação profissionalizante do País. Neste contexto, as escolas profissionalizantes cumpriam o papel de reprodução da força de trabalho. Para ela, "os governos Lula e Dilma vêm demonstrar a permanência da imposição do projeto do capital na formação profissional" (SILVA, 2016, p. 37). Ao reforçar a lógica da mercadoria, o PRONATEC não rompe, segundo Silva (2016), com a dinâmica do capital que oferece uma formação apenas enquanto mão de obra barata, encobrindo sob o signo do empreendedorismo o trabalho precário e o auto-emprego.

Como evidenciado nos parágrafos anteriores, o PBF e o PRONATEC adotam uma definição bem delimitada de quem são os pobres, com foco nos aspectos financeiros. Essa definição não foi fruto do acaso ou do desenvolvimento de teoria autóctone sobre os problemas sociais. Pelo contrário, o governo agiu informado por técnicos que se vincularam à produção teórica e recomendações acerca da pobreza, dos pobres e de como efetivar o seu combate, vindas dos países centrais e de organismos multilaterais. Particularmente, as propostas do Banco Mundial, de Amartya Sen e do PNUD parecem ser fundantes para esses programas e seus analistas.

A partir desses referentes teóricos e das recomendações técnicas deles decorrentes, o combate à pobreza reduz-se à inclusão dos indivíduos classificados como pobres nos mecanismos de mercado, seja através da oferta de um benefício monetário condicionado, seja de uma suposta qualificação profissional que habilitaria os indivíduos ao mercado de trabalho. Como criticado até mesmo por seus analistas mais comedidos, são várias as limitações dos Programas. Elas permitem inscrevê-los na trajetória das políticas compensatórias liberais, isto é, que, separam o social da economia; que concebem a pobreza como um problema individual, ignorando seus determinantes históricos. Pela relevância dessas abordagens, esses autores e instituições são o tema desenvolvido na próxima seção.

\section{PRINCIPAIS REFERÊNCIAS PARA COMPREENDER A POBREZA E SEU COMBATE}

Háde se reconhecerque o Governo não definiu arbitrariamente a pobreza e, a partir dá, criou o Bolsa Família. Pelo contrário, agiu informado por técnicos e pesquisadores que se vincularam à 
produção teórica e recomendações acerca da pobreza, dos pobres e de como efetivar o seu combate, vindas dos países centrais e de organismos multilaterais. Dentre as principais referências para o temam, como já mencionado, destacam-se as obras de John Rawls, Amartya Sen e Milton Friedman e documentos oficiais do Programa das Nações Unidas para o Desenvolvimento (PNUD) e do Banco Mundial. Essas referências constituem um corpo não-coeso sobre a pobreza e como deve ocorrer o seu combate.

Apesar de não poderem ser justapostos, esses autores e instituições compartilham interpretações liberais dos Programas Sociais de Combate à Pobreza, centradas na ideia do pobre como um indivíduo destituído de oportunidades nos mecanismos de mercado. A essas interpretações é circunscrito o tema do desenvolvimento, entendido como crescimento econômico, que pode ser associado a adjetivos variados, isto é, desenvolvimento mundial (WORLD BANK, 1973), desenvolvimento humano (PNUD, 1990) e desenvolvimento como liberdade (SEN, 2000).

Autores ligados a essa concepção partem da ideia de que o crescimento econômico não gerou o fim da pobreza (FRIEDMAN, 1966; WORLD BANK, 1973; SEN, 2000) e que, portanto, é preciso ajudar os pobres a se ajudarem (WORLD BANK, 2011). Nessa sociedade, os indivíduos possuem capacidades e oportunidades desiguais, que tentam realizar por meio de funcionamentos valorizados individualmente. Aí reside a essência da ideia de desenvolvimento como liberdade, isto é, na criação de oportunidades para que os indivíduos realizem as suas capacidades por meio de funcionamentos por eles valorizados (SEN, 1997; 2000).

Sen (1997, p.1) entende que as desigualdades entre os indivíduos podem ser prejudiciais para o funcionamento das sociedades, pois "a desigualdade é um ingrediente comum da rebelião, mas também é importante reconhecer que a percepção da desigualdade, e o conteúdo desse conceito, depende substancialmente das possibilidades de uma rebelião de fato". A partir daí, é possível pensar em uma abordagem das desigualdades econômicas que seja capaz de minimizar as possibilidades de revolta popular. Nela, Sen (1997;2000) propõe a adoção de mecanismos de empoderamento financeiro, realizada a partir de comparações pontuais entre indivíduos, visando reduzir as desigualdades.

Desde a perspectiva liberal, os Programas Sociais de Combate à Pobreza podem operar em duas frentes. Em uma delas, esses Programas oferecem uma renda mensal para os pobres e miseráveis, seguindo a lógica de um imposto de renda negativo de Friedman (1966), isso é, oferecem um subsídio monetário para aqueles que não atingem 
determinada renda. Com isso, "se enfrenta diretamente o problema da pobreza. Ajudando o indivíduo na forma que mais lhe é útil, com dinheiro. É o modo mais geral e poderia substituir uma série de medidas existentes na atualidade. [...] Cada dólar que se ganha significa mais dinheiro disponível para gastar (FRIEDMAN, 1966, p. 244).

Já na outra frente de combate à pobreza, os Programas Sociais devem investir em capital humano, com a intenção de aumentar a produtividade dos trabalhadores através de programas de qualificação profissional. A educação profissional e o treinamento são advogados, pois segundo os autores de orientação liberal, aumentam a renda dos trabalhadores a partir do aumento da sua produtividade. Becker (1993, p.15) entende como capital humano a "educação formal, um curso de informática, gastos com cuidados médicos, palestras sobre as virtudes da pontualidade e da honestidade, pois eles melhoram a saúde e aumentam os ganhos dos indivíduos".

As políticas de transferência de renda e de qualificação profissional proporcionam uma distribuição de dinheiro, de modo que o cumprimento de um imperativo moral gera, ao mesmo tempo, "escolhas e oportunidades para viver uma vida tolerável" (PNUD, 1997, p. 15), expandindo os mecanismos de mercado. A partir desse referencial, o combate à pobreza seria operado pela ampliação das escolhas e das liberdades dos indivíduos nos mecanismos de mercado, espaço de realização pessoal.

Olhando para o PRONATEC desde esse referencial, é notório que o Programa manteve certo conservadorismo na concepção da pobreza como um problema individual do pobre que possuía repercussão familiar e assolava grande contingente humano. No entanto, a essa premissa, foram incorporados elementos de um discurso que defende a ampliação dos direitos sociais e a necessidade da afirmação da cidadania ativa do pobre. Esse novo aspecto do combate à pobreza se deveu à aproximação entre o Governo Federal e setores da sociedade que leem a questão social desde a necessidade da retomada do avanço de direitos constitucionais conquistados, na inspiração de um Estado de Bem-Estar Social.

Partindo de pressupostos diferentes da visão liberal, essa interpretação da 'questão social' dos Programas Sociais de Combate à Pobreza concebe a ampliação dos direitos sociais e o fortalecimento da cidadania como condição para a superação da pobreza. Os autores que tratam da questão social possuem em comum o pressuposto de que nos países da América Latina, o crescimento econômico orquestrado via desregulamentação do mercado exigiu o sacrifício da questão social (IVO, 2006; TELLES, 2006). 
Cabe ressaltar que a questão social não é uma abordagem uníssona. Os autores vinculados a essa interpretação compartilham referenciais e o pressuposto da insuficiência do neoliberalismo para dar conta da questão social, mas essa própria questão surge das inquietações que vêm sendo formuladas de formas diversas por tantos quantos se debruçam sobre a realidade regional (TELLES, 2006:53).

Autores que partilham dessa abordagem compreendem que a pobreza é produzida socialmente (LEGUIZAMON, 2005), ao passo que a pobreza nos países latino-americanos decorre da globalização e da transformação neoliberal que o capitalismo mundial produziu ali. Para Leguizamón (2005, p. 41), as causas da pobreza massiva na América Latina são: 1) "a impossibilidade de gerar renda pela via da condição de assalariado formal"; 2) "a reforma do mercado de trabalho, a flexibilização laboral e a falta de cobertura de direitos vinculados ao trabalho", como a seguridade social; 3) a impossibilidade de acesso a outros meios de subsistência, como "o acesso à terra, à água ou ao crédito".

Como resultado desse processo de transformação das condições de reprodução social a sociedade não consegue traduzir direitos proclamados em parâmetros mais igualitários de ação. Para Telles (2006, p. 88), isso é sinal de uma população destituída de seus direitos. "A pobreza brasileira não deixa, de fato, de ser enigmática em uma sociedade que $[. .$.$] mal ou bem fez a sua entrada na modernidade$ e proclama, por isso mesmo, a universalidade da lei e dos direitos nela sacramentados". Ainda de acordo com essa autora, a persistência da pobreza tem raízes seculares, mas apresenta também uma face contemporânea, registrada no empobrecimento dos trabalhadores urbanos integrados nos centros dinâmicos da economia do país.

Os Programas de Transferência Condicionada de Renda são percebidos por esses autores como parte do substrato discursivo do desenvolvimento humano no marco da governabilidade neoliberal, que aparenta preocupação com os pobres, mas que não promove a mudança das estruturas sociais nem das relações que produzem e reproduzem a pobreza e a exclusão (LEGUIZAMÓN, 2005).

Para Leguizamón (2005), os Programas são, na expressão proposta pela autora, focopoliticas, isto é, um modo de governar preocupado com a provisão de mínimos que se traduzem em benefícios aos pobres, ao mesmo tempo em que reduzem os direitos sociais. A autora critica, ainda, a adoção da linha de pobreza extrema em 1 dólar PPC, ao invés das linhas de pobreza nacionais, pois se essa medida facilita as comparações entre países, ignora suas características peculiares e nivela por baixo a pobreza, pois diminui o número oficial 
de miseráveis e indigentes, sem alterar substancialmente a situação de vulnerabilidade em que essas pessoas vivem.

Para os autores vinculados a essa abordagem, o combate à pobreza deve ser situado desde uma perspectiva política, que critica a degradação dos serviços públicos, o desemprego e as relações trabalhistas fragilizadas, visando a ampliação dos direitos sociais e da cidadania. Para esses autores, os pobres são "os não-iguais, os que não estão credenciados à existência cívica justamente porque são privados de qualificação para o trabalho. São os pobres, figura clássica da destituição. Para eles, é reservado o espaço da assistência social, cujo objetivo não é elevar condições de vida mas minorar a desgraça e ajudar a sobreviver na miséria" (TELLES, 2006, p. 94).

Os autores vinculados a essa interpretação defendem a ampliação do acesso aos Programas Sociais e a sua melhoria a partir da inclusão de parcelas da sociedade no seu planejamento. Para eles, mais do que focopolíticas ou instrumentos compensatórios que pouco alteram a situação de vulnerabilidade dos pobres, essas Políticas podem favorecer a constituição de uma cidadania ativa, isto é, o exercício dos poderes de ação de sujeitos comprometidos com a comunidade a que pertencem de modo que, pela sua ação organizada, consigam algum tipo de eficácia política.

Para que haja uma compreensão mais clara dos avanços, efeitos e limitações do PBF e PRONATEC é necessário cotejar as interpretações liberais e da 'questão social' com uma interpretação que tradicionalmente se volta para o pobre e para a pobreza, criticando o mercado como lócus da realização da vida humana. Encontramos na Filosofia da Libertação, de Enrique Dussel, o fundamento que torna possível empreender essa análise.

A Filosofia da Libertação constitui um arcabouço teórico importante desde onde analisar a reprodução da pobreza desde as particularidades do sistema capitalista na América Latina. Dussel (2002, p. 573) propõe uma práxis orientada pelo princípio universal da "produção e reprodução da vida de cada sujeito humano", necessária "nesta época da história, no final do século XX e começo do III milênio, especialmente para as vítimas excluídas do atual processo de globalização do capitalismo mundial" (DUSSEL, 2002, p. 572). Essa Filosofia articula uma ética, uma pedagogia, uma teologia, uma política e uma economia voltadas para a libertação dos pobres.

Abordar o PBF desde essa perspectiva exige evidenciar a natureza relacional da produção social da pobreza, isto é, que a pobreza é o correspondente de um processo de acumulação de riqueza. Esse pressuposto surge da constatação das condições de vida 
de dois terços da população da América Latina, frente à pujança de uma minoria (DUSSEL, 2002).

Nos países latino-americanos, o processo contemporâneo de acumulação de riquezas tem como contexto a globalização das economias, que reforça a dependência desses países em relação aos centrais, e a orientação liberal dos governos que substituíram as ditaduras predominantes até a década de 1980.

Dussel compreende filosoficamente a transferência de valor oriunda da exploração de uma classe sobre a outra, analisada por pensadores da Teoria Marxista da Dependência, como Ruy Mauro Marini. Essa transferência de valor começa a ganhar forma no processo produtivo, pois é na produção de mercadorias que se cria o valor que será transferido. Portanto, para que se possa compreender o modo como a transferência ocorre é necessário conhecer as peculiaridades em torno do trabalho nas economias periféricas.

De acordo com Marini (2005, p. 143), essas economias são marcadas pela divisão internacional do trabalho, que determina o sentido do desenvolvimento da região. É desde aí que se configura a dependência, entendida como "uma relação de subordinação entre nações formalmente independentes, em cujo marco as relações de produção das nações subordinadas são modificadas ou recriadas para assegurar a reprodução ampliada da dependência". Para o autor, a consequência da dependência não pode ser, portanto, nada mais do que maior dependência, e sua superação supõe necessariamente a supressão das relações de produção nela envolvida.

De modo a tentar diminuir as perdas decorrentes desse mecanismo de transferência de valor, as nações desfavorecidas criam mecanismos de compensação visando o incremento do valor trocado. Para conseguir o aumento do valor produzido, os capitalistas das economias dependentes devem lançar mão de uma maior exploração da força de trabalho, "seja através do aumento de sua intensidade, seja mediante a prolongação da jornada de trabalho, seja finalmente combinando os dois procedimentos" (MARINI, 2005, p. 153)

$\mathrm{O}$ autor identifica três procedimentos operados pelos capitalistas nesse mecanismo interno de compensação das trocas desiguais. Em resumo, os três procedimentos identificados são a "intensificação do trabalho, a prolongação da jornada de trabalho e a expropriação de parte do trabalho necessário ao operário para repor sua força de trabalho". Nos dois primeiros casos o trabalhador é obrigado a um dispêndio de força de trabalho superior ao que deveria proporcionar normalmente, "provocando assim seu esgotamento prematuro"; no terceiro caso, é retirado do trabalhador a possibilidade 
de consumo do estritamente indispensável para conservar sua força de trabalho em estado normal. "Em termos capitalistas, esses mecanismos significam que o trabalho é remunerado abaixo de seu valor e correspondem, portanto a uma superexploração do trabalho" (MARINI, 2005, p. 156). Nesse sentido, o efeito das trocas desiguais entre as nações é o de exacerbar o afã do capitalista por lucro e aguçar os métodos de extração de trabalho excedente.

A superexploração do trabalho decorre de articulações complexas entre os três procedimentos apontados e configura a base que as economias dependentes latino-americanas adotaram para seu regime de acumulação. Este, por sua vez, é o correspondente regional do processo de acumulação vigente nos países centrais que se realiza, em parte, pelas trocas desiguais entre esses países e os dependentes.

Com essa exposição consolidada das três principais interpretações acerca da pobreza e de seu combate no Brasil, podemos proceder à apresentação e análise dos dados.

\section{APRESENTAC̣ÃO E ANÁLISE DOS DADOS}

Os dados apresentados e discutidos a seguir foram coletados em entrevistas qualitativas com beneficiários do Programa Bolsa Família, trabalhadores da Secretaria Municipal de Assistência e Inclusão Social de Sant'Ana do Livramento vinculados ao Programa e representante do SENAC de Livramento que atua nos cursos PRONATEC. Rapley (2004) classifica como entrevistas qualitativas os encontros sociais nos quais os falantes colaboram em produzir versões retrospectivas (e prospectivas) de suas ações, experiências, sentimentos e pensamentos passados (e futuros). Essa classificação visa superar a confusão que sobre o quê, especificamente, faz uma entrevista em profundidade uma "entrevista em profundidade", quando comparada com as entrevistas que a literatura acadêmica classifica como: ativa, biográfica, colaborativa, conversacional, profunda, dialógica, focada, guiada, informal, história de vida, não dirigida, open-ended, história oral, reflexiva, semiestruturada, entre outras (RAPLEY, 2004). Os nomes nas passagens em itálico a seguir são fictícios, visando preservar a identidade dos entrevistados.

A seleção de Sant'Ana do Livramento como cidade para realizar esse estudo se justifica pela presença da sede de um SENAC, por ser um dos primeiros municípios do Rio Grande do Sul a pactuar a oferta de cursos do PRONATEC junto ao Governo do Estado e ao SENAC e, principalmente, pela sua característica singular de fronteira seca com a cidade uruguaia de Rivera, com que compartilha uma larga 
avenida e o Parque Internacional da Paz. Sant'Ana do Livramento está localizada a pouco menos de 500 quilômetros da capital dos gaúchos, na região sudoeste do Rio Grande do Sul. A sua história de Sant'Ana remonta a 30 de junho de 1823, quando foi criada a vila de Nossa Senhora do Livramento, emancipada de Alegrete em 10 de fevereiro de 1857. A cidade apresenta atualmente uma população superior a 80.000 pessoas (IBGE, 2010) distribuídas em uma área de 6.950,4 $\mathrm{km}^{2}$. O seu Índice de Desenvolvimento Humano médio atribuído pelo PNUD foi 0,803, superior ao do Brasil, 0,699 e um pouco inferior à média estadual de 0,814 . O PIB per capta no ano de 2008 foi estimado em $\mathrm{R} \$ 10.484,00$ (FEE, s/d), apesar da incidência de pobreza de cerca de 30\% (IBGE, 2010). Mesmo com uma industrialização precoce, a base da economia santanense atual é o setor terciário, responsável por mais de $60 \%$ do PIB, seguido de longe pelo setor agropecuário (IBGE, 2010). No entanto, é importante ressaltar o fato de que desses 80.000 habitantes, somente pouco mais de 13.000 são assalariados, o que representa aproximadamente $16 \%$ da população total.

Do lado uruguaio, a história da fundação de Rivera remonta à fundação do Pueblo Ceballos em 1862, em memória a um nobre espanhol que expulsou os portugueses da cidade de Colônia de Sacramento e invadiu o Brasil por duas vezes. A cidade de Rivera foi criada em 20 de julho de 1867, para controlar a nacionalidade brasileira em expansão na faixa de fronteira (ASEFF, 2009). Rivera é a sede do Departamento homônimo e possui uma população de aproximadamente 64.000 habitantes (INE, 2008). O Departamento de Rivera apresenta um Índice de Desenvolvimento Humano semelhante ao de Livramento e um PIB superior a US\$350.000,00. Deste, mais de $60 \%$ tem origem em atividades terciárias, originadas, mormente pelas lojas de duty free (INE, 2008).

Se a história da criação das duas cidades esteve marcada por razões estratégicas para os governos brasileiro e uruguaio, a convivência diária, as necessidades em comum e a ausência de barreiras consolidaram uma história conjunta bastante peculiar a esse povo fronteiriço. "Nessa fronteira, pode-se dizer, o limite territorial entre o Brasil e o Uruguai atravessa ambos os centros urbanos, embora também seja possível afirmar o contrário: são as cidades as que parecem atravessar o limite político internacional, e é isso o que torna essa fronteira uma região tão singular" (ASEFF, 2009: 14). Esse contexto de dinamismo social e singularidade de duas cidades que se fundem marca a realização de nossa pesquisa sobre a contribuição dos cursos PRONATEC oferecidos pelo SENAC de San'Ana do Livramento para a inserção profissional na região. 
Os cursos oferecidos dentro da iniciativa PRONATEC são pagos pelo Governo e os estudantes recebem as passagens de ônibus e um vale-lanche para cada dia de curso. Inicialmente os cursos oferecidos pelo PRONATEC eram oferecidos apenas para membros de famílias beneficiárias do Bolsa Família, principalmente para jovens acima de 16 anos que buscavam qualificação para ingressarem no mercado de trabalho. De acordo com Joana, uma das pessoas responsáveis pelos cursos PRONATEC do SENAC Livramento, a lógica do Programa se alterou. A inscrição no Programa passou a ser feita pelo sítio eletrônico do PRONATEC e qualquer pessoa pode se inscrever, independente de ser ou não de família beneficiária do Bolsa Família. Essa mudança foi bastante celebrada pelos SENAC, pois, como afirma Joana, "houve um aumento muito rápido no número de alunos matriculados. Em 2012, foram matriculados 302 (trezentos e duas) pessoas nos cursos. Em 2013 esse número saltou para 605 (seiscentos e cinco) até o mês de junho [os dados dos meses seguintes ainda não haviam sido consolidados]". Ela contou que os cursos passaram a ser divulgados nas rádios e nos jornais da cidade e, dificilmente, ela não inicia uma turma sem ter todas as vagas preenchidas: "O SENAC é uma empresa. A nossa meta é sempre os $100 \%$ ".

A alteração no formato de oferta dos cursos PRONATEC traz impactos sérios para a realização dos objetivos do Brasil Sem Miséria, pois a sua vinculação exclusiva com os beneficiários do Bolsa Família fazia vezes da chamada 'porta de saída' do Programa, articulando o incremento da renda familiar com a qualificação profissional, ideias coerentes com a abordagem do capital humano e do desenvolvimento de capacidades. Essa alteração favoreceu o caráter comercial dos cursos oferecidos pelo SENAC, expandindo o seu nicho de mercado, em detrimento do objetivo social do PRONATEC.

Em entrevista com Patrícia, uma das pessoas responsáveis pelo cadastramento dos beneficiários do Bolsa Família na Secretaria de Assistência e Inclusão Social de Livramento, ela define o perfil dos beneficiários: "geralmente são mulheres de meia idade, mãe solteira, com mais ou menos três filhos, que mora em bairros pobres e trabalha como doméstica ou com changas (trabalho informal e ocasional em casa de família ou no campo). A maioria delas apenas terminou o quinto ano do ensino fundamental e muitas escondem o marido com medo de perder o direito ao benefício". Em entrevista com beneficiários do Programa, com perfil bastante próximo ao delimitado por Patrícia, questionamos sobre o conhecimento dos cursos PRONATEC. As falas de entrevistadas ilustram a dinâmica do mercado de trabalho local e das suas condições de vida. 
Berenice, 19 anos, mãe solteira de Theo, 4, completou o ensino fundamental e trabalha com faxina. O pai de Theo a abandonou quando ela engravidou e não oferece qualquer ajuda financeira. Ela está aguardando para receber o Bolsa Família e faz faxina: "para ir trabalhar, eu tenho que pagar a minha vizinha pra olhar o guri depois que ele sai da creche... Muita madame não gosta de faxineira com criança pequena". Berenice afirma receber mais ou menos $\mathrm{R} \$ 400,00$ (quatrocentos reais) por mês. $R \$ 150,00$ são utilizados para pagar o aluguel de um quarto-sala com banheiro; $\mathrm{R} \$ 200,00$ ela gasta no supermercado, $\mathrm{R} \$ 30,00$ em energia elétrica, $\mathrm{R} \$ 20,00$ são utilizados em transporte e emergências com Theo. Quando perguntada se gostaria de poder estudar mais ela afirma que "eu queria estudar mais, mas não dá para pagar minha vizinha todo dia para olhar o guri".

Em um dos Centros de Referência em Assistência Social (CRAS) da cidade, entrevistei Teresa, que tinha ido incluir seu filho mais novo no cadastro do Bolsa. Teresa trabalha como diarista "em duas casas de familia", tem uma filha de 16 anos e um bebê de 10 meses. Seu marido trabalha em uma fazenda, com carteira assinada. Teresa teme perder o Bolsa Família "porque a Maiara não está indo para a escola e o nenê ainda não está cadastrado". A sua família é beneficiária há bastante tempo e o valor recebido pelo Programa "é juntado com o salário do men marido e com o que eu ganho. Todos nós usamos". Sobre o medo de perder o benefício, Teresa disse "Ah, meu filho! Quem é pobre está acostumado a perder. Fazer o quê? Não tem jeito. O que eu posso fazer? Eu queria muito que a Maiara terminasse a escola para ela tentar achar um trabalho". Teresa ouviu falar dos cursos do PRONATEC, mas não acha que ela ou sua filha possam cursá-los. Quando Teresa sai para trabalhar, a sua filha precisa ficar em casa para cuidar do bebê.

Tive a oportunidade de acompanhar a equipe de um CRAS a uma visita domiciliar a uma beneficiária do Bolsa Família que não havia feito o recadastramento obrigatório a cada dois anos e nos telefones cadastrados não funcionavam. Chegamos à casa de Fernanda que estava com a porta e as janelas fechadas - parecia abandonada. A assistente social precisou gritar o nome de Fernanda várias vezes até que ela aparecesse à porta. Fernanda nos convidou a entrar, pedindo desculpas pela bagunça e pela sujeira, mas ela estava doente e não podia limpar a casa, "que é emprestada de uma amiga. Quando eu posso, eu dou um dinheirinho pra ela. Mas não tá fácil”. Fernanda tem 38 anos e é mãe de quatro filhas, "a mais velha tá casada, graças a Deus. A do meio mora com a madrinha, e tem as gêmeas, né? Elas tão com 12 anos e moram com a avó”. Fernanda recebe R $\$ 252,00$ do Bolsa Família e dá todo o valor para sua mãe, por causa das filhas que moram com 
ela. Seu marido a abandonou quando as gêmeas ainda eram recémnascidas. "Ele era caminhoneiro, foi trabalhar e nunca mais apareceu. Não sei se tá vivo ou morto". Fernanda se surpreendeu com a notícia de que seu benefício seria bloqueado por falta de recadastramento e disse que o dinheiro havia sido bloqueado três vezes no último ano e que teve de ir à Secretaria três vezes para resolver o problema. " $\mathrm{Na}$ Caixa me disseram que o meu cartão não tava mais valendo e que eu tinha que receber apenas com essa boleta agora" - Fernanda mostrava um recibo da Caixa Econômica Federal, agente pagador do Bolsa Família, com um número de benefício diferente do registrado pela assistente social. Fernanda trabalha vendendo cosméticos de uma revista de alcance mundial e espera que "as meninas tenham um destino melhor que o meu, apesar das coisas tarem mais difícil hoje em dia pra todo mundo". Perguntei a Fernanda se ela conhecia o PRONATEC e se não pensava em fazer um curso de qualificação profissional. "Pra quê? Pra trabalhar em quê?? Não tem trabalho em Livramento, por isso tá todo mundo indo embora. Eu acho que vou pra São Paulo ano vem. Meu irmão tá morando lá. Eu vendo produto [de beleza] de porta em porta. Ninguém tem dinheiro".

Esses trechos mostram que o PRONATEC não alcança exatamente o público que originariamente havia sido delimitado para atendimento, as famílias beneficiárias do Bolsa Família. As justificativas apresentadas para não participarem dos cursos do PRONATEC articulam questões estruturais como o mercado de trabalho em Livramento, a necessidade de trabalhar para sustentar a família e o cuidado com os filhos. As entrevistas também colocam em xeque a suposição do sensocomum de que os beneficiários do Bolsa Família se tornam preguiçosos e deixam de trabalhar para viver às custas do Programa.

$\mathrm{Na}$ entrevista com a representante do SENAC de Sant'Ana do Livramento questionei Joana sobre o impacto social dos cursos PRONATEC para a economia local. Ela afirmou que "[N]ós nunca fizemos uma pesquisa com os empresários da cidade. Só sei que quando passo pelas lojas eu vejo as carinhas conhecidas e sei que foram nossos alunos. Mas não posso te dizer um número". Joana disse que algumas empresas procuram o SENAC em busca de indicação de ex-alunos, mas não é parte da política do SENAC sugerir estudantes para vagas, porque "todos os nossos alunos que concluíram o curso foram capacitados e têm a mesma capacidade de conseguir uma chance no mercado... Nós enviamos uma lista com os nomes de quem concluiu um curso de acordo com o perfil que a empresa solicitou”. O SENAC também não faz um controle se os alunos PRONATEC já estavam inseridos no mercado de trabalho e procuraram qualificação para encontrarem melhores vagas, se estavam em busca do primeiro emprego ou se eram desempregados que buscavam reinserção. 
O PRONATEC teve seus objetivos alterados de uma política social de educação técnica complementar ao Bolsa Família, oferecendo uma 'porta de saída' aos beneficiários que completavam a idade limite para recebimento do Bolsa com a qualificação para tentar inserção no mercado de trabalho para se tornar um curso gratuito de acesso ampliado. Essa alteração não apenas serviu para incrementar a fatia de mercado do SENAC através da oferta de cursos pagos pelo Governo, como também contribui para a divulgação da fantasia de que a educação profissional cria oportunidades melhores - mesmo em contextos socioeconômicos difíceis como o de Sant'Ana do Livramento.

\section{CONSIDERAÇ̃̃ES FINAIS}

As alterações ocorridas no PRONATEC em seu pouco tempo de existência demonstram que esse Programa abandonou o propósito de ser um Programa complementar que operaria a saída qualificada do Bolsa Família, atuando diretamente no combate à pobreza, para se circunscrever aos interesses dos agentes oferecedores dos cursos. Com o aumento do número de alunos, decorrente dessa mudança, certamente há um incremento do valor repassado pelo Governo. Não há mais relação direta entre o PRONATEC e o Bolsa Família, rompendo também o vínculo dos cursos com a erradicação da pobreza.

Os Programas Sociais do Governo Federal, seja de qualificação profissional ou de transferência condicionada de renda, mantiveram a ideia liberal da pobreza como um problema individual do pobre que possui repercussão familiar e assola grande contingente humano. Esse número foi quantificado a partir dos parâmetros das Linhas de Pobreza e de Pobreza Extrema, que possibilitaram executar um combate focalizado à pobreza. Essa focalização baseou-se na definição de um perfil único de público-alvo a ser privilegiado com a sua implantação, visando aliviar a pobreza para a totalidade dessa parcela específica da população. De acordo com Kerstenetzky (2009, p. 64), "é perfeitamente focalizado o programa que transfere recursos para todas as pessoas elegíveis e apenas para elas. Essa é a definição, por assim dizer, primária de eficiência de programas focalizados." Desde aí, a condição de vida dos pobres poderia ser combatida a partir de ações moralizantes de caráter normalizador, isto é, atribuindo condicionalidades na saúde e educação ao recebimento do benefício monetário. De acordo com as suas premissas subjacentes, os PTCs habilitariam aos pobres ingressar nos mecanismos de mercado, graças a um suposto empoderamento monetário e ao aumento da sua empregabilidade, decorrente do incremento do capital humano. $\mathrm{O}$ 
PRONATEC foi criado como intuito de incrementar essa empregabilidade a partir da qualificação individual para tornar jovens ex-beneficiários do Bolsa Família e seus responsáveis habilitados ao mercado de trabalho.

Os dados coletados indicam que mesmo esse objetivo de forte matiz liberal não se realizou na prática. Com a submissão dos objetivos do PRONATEC aos imperativos do mercado de cursos profissionalizantes, a inclusão das pessoas nos mecanismos de mercado ganha uma fachada moral que é vazia de significado. A suposta qualificação profissional oferecida pelo Programa não pode ter os seus efeitos verificados na realidade local em que ela se insere. $\mathrm{O}$ apelo à educação profissional não é uma garantia de que haverá postos de trabalho para todos aqueles que são treinados. No âmbito do PRONATEC impera a lógica da competição entre pessoas necessitadas em um contexto marcado por dificuldades econômicas e vulnerabilidade social.

Cabe retomar alguns questionamentos apontados por Cohn (2012, p. 25), para quem ainda há que se definir o significado do Programa Bolsa Família em termos do seu conteúdo social. "A questão é: sua configuração básica consiste meramente em constituir-se como um programa transversal de transferência de renda condicionada, com vistas ao alívio imediato da pobreza? Ou será um programa estruturante, voltado à construção da cidadania e da autonomia dos sujeitos sociais, seus beneficiários"?

As evidências da relação entre o PBF e o PRONATEC são indícios de que a resposta a essa pergunta feitas por Amélia Cohn já está dada. Sem se constituir em um direito de garantia de renda mínima, sem instâncias organizadas de participação cidadã autônoma e com dificuldades em oferecer uma 'porta de saída' aos beneficiários, o combate à pobreza no Brasil, conduzido no bojo desses dois Programas Sociais está sustentado por preceitos liberais, que confundem a afirmação de direitos sociais com a inserção nos circuitos do consumo.

\section{REFERÊNCIAS}

ASSEF, M. Retratos do Exílio: solidariedade e resistência na fronteira. Santa Cruz do Sul/ RS: EDUNISC, 2009.

BECKER, G. S. "Human Capital", The Concise Encyclopedia of Economics. Library Economics and Liberty, Indianapolis, Liberty Fund, 2008. Available at: <http://www. econlib.org/library/Enc/HumanCapital.html>. Access: 17 apr. 2012.

BETTO, Frei. Frei Betto critica assistencialismo e pede reformas por 'democracia econômica'. UOL. UOL Notícias, São Paulo, 15 mar. 2008. Disponível em: < http://noticias.uol.com. br/ultnot/2008/03/15/ult23u1484.jhtm>. Acesso em: 15 abr. 2013. 
BRASIL. República Federativa do Brasil. Presidência da República. Casa Civil. Lei n⿳0 10.836, de 09 de janeiro de 2004. Brasília, 2004. Disponível em: <http://www.planalto.gov.br/ ccivil_03/_ato2004-2006/2004/lei/110.836.htm>. Acesso em: 12 jan. 2013.

BRASIL. Portal da Transferência do Governo Federal. Transferência de Recursos por Ação de Governo. Brasilia: 2012a. Disponível em: <https://goo.gl/pDoWF4>. Acesso em: 13 abr. 2012.

BRASIL. Ministério da Educação. Programa Nacional de Acesso ao Ensino Técnico e Emprego. O que é o PRONATEC. Brasília: 2012b. Disponível em: <http:// PRONATECportal.mec.gov.br/PRONATEC.html>. Acesso em: 17 abr. 2013.

BRASIL. Brasil. Presidência da República. "Relatório Nacional de Acompanhamento", in Brasil, Objetivos de Desenvolvimento do Milênio, Brasília: IPEA, 2012.

BRONZO, C. Vulnerabilidade, empoderamento e proteção social. Reflexões a partir de experiências Latinoamericanas. In: XXXII EnANPAD, 2008. Anais... Rio de Janeiro, 2008.

BRONZO, C. Políticas locais de inclusão social, autonomia e empoderamento: reflexões exploratórias. In: XXX EnANPAD, 2006. Anais... Salvador, 2006.

COHN, A. Cartas ao Presidente Lula: Bolsa Família e Direitos Sociais. Rio de Janeiro: Pensamentos e Intervenções, 2012.

COSTA, M. I. Proteccion Social Universal: el caso de la Asignación Universal por Hijo para Protección Social en la Argentina. Debates políticos, ejes de ruptura y continuidad. In: MIDAGLIA, C.; REYES, V.; ZICCARDI, A. (coord.). Persistencias de la pobreza y esquemas de protección social en América Latina y el Caribe. Buenos Aires: CLACSOCROP, p. 221-249, 2013.

DEITOS, R. A.; LARA, A. M.; ZANARDI, I. M. Política de Educação Profissional no Brasil: aspectos socioeconômicos e ideológicos para a implantação do PRONATEC. Educ. Soc., Campinas, v. 36, n. 133, p. 985-1001, out.-dez., 2015.

DUSSEL, E. Ética da Libertação na Idade da Globalização e Exclusão. $2^{a}$ ed. Petrópolis: Vozes, 2002.

FEE. Fundação de Economia e Estatística. Resumo Estatístico RS. Município: Sant'Ana do Livramento. Porto Alegre, s/d. Disponível em: <http://www.fee.tche.br/sitefee/pt/ content $/$ resumo/pg_municipios_detalhe.php?municipio $=$ Santana + do + Livramento $>$. Acesso em: 28 abr. 2013.

FRIEDMAN, M. Essays in Positive Economics. Chicago: Chicago University Press, 1966.

GLUZ, N.; MOYANO, I. R. Asignación Universal por Hijo, condiciones de vida y educación: las políticas sociales y la inclusión escolar en la provincia de Buenos Aires. Archivos Analíticos de Políticas Educativas, n.21, v. 21, p. 1-28, 18 mar. 2013.

GUERRA, A. C. et al. Programa Bolsa Família: uma análise do ponto de vista dos usuários. In: XXXV EnANPAD, 2011. Anais... Rio de Janeiro, 2011.

HELAL, D.; NEVES, J. Superando a Pobreza: o Papel do Capital Social na Região Metropolitana de Belo Horizonte. In: XXX EnANPAD, 2006. Anais... Salvador, p. 1-18, 2006. 
IBGE. Instituto Brasileiro de Geografia e Estatística. Censo Demográfico 2010. Disponível em: <http://ibge.gov.br/home/estatistica/populacao/censo2010/default_uf.shtm>. Acesso em: 02 mai. 2013.

INE. Instituto Nacional de Estadística. Censo Economico. Montevidéu, 2008. Disponível em: http://www.ine.gub.uy/economia/censo\%20economico2008.asp. Acesso em: 02 mai. 2013.

IVO, A. B. L. "A Reconversão da Questão Social e a Retórica da Pobreza nos anos 1990". In: CIMADAMORE, A.; DEAN, H.; SIQUEIRA, J. (org.). A pobreza do Estado: reconsiderando o papel do Estado na luta contra a pobreza global. Buenos Aires: CLACSO Livros, 2006.

LEGUIZAMÓN, S. A. Trabajo y producción de la pobreza em Latinoamérica y el Caribe: estructuras, discursos y actores. Buenos Aires: CLACSO Libros, 2005.

MARINI, R. M. Dialética da Dependência. In: TRASPADINI, R.; STEDILE, J. P. (org.). Ruy Mauro Marini: vida e obra. São Paulo: Expressão Popular, 2005.

MEDEIROS, M. R. A.; COUTO, B. R. Programas de Transferência de Renda: debate no âmbito da produção social. In: SILVA, V. R.; MENDES, J.; FAGUNDES, H.; AGUINSKY, B. Política Social: temas em debate. Pelotas: EDUCAT, p. 23-47, 2009.

MOREIRA, N. et al. Dimensões do Empoderamento das Mulheres Beneficiárias do Programa Bolsa Família. In: XXXV EnANPAD, 2011. Anais... Rio de Janeiro, 2011.

NASSIF, Luis. A Vitória do Bolsa Família. Carta Capital, São Paulo, 02 jul. 2012. Disponível em: <http://www.cartacapital.com.br/economia/a-vitoria-do-bolsa-familia> Acesso em: 08 set. 2013.

O GLOBO. Jornal O Globo. País. Bolsa Família completa 10 anos, Rio de Janeiro, 5 mai. 2013. Disponível em: <http://oglobo.globo.com/infograficos/especial-bolsa-familia/>. Acesso em: 6 mai. 2013.

PNUD. Programa das Nações Unidas para o Desenvolvimento. Human Development Report 1997. 1997. Disponível em: <http://hdr.undp.org/en/reports/global/hdr1997/ chapters/>. Acesso em: 21 fev. 2013.

PNUD. Human Development Report 1990. New York: Oxford University Press, 1990. Disponível em: <http://hdr.undp.org/en/reports/global/hdr1990/chapters/>. Acesso em: 21 jun. 2011.

POCHMANN, M. Políticas Públicas e Situação Social na Primeira Década do Século XXI. In: SADER, E. (org.). 10 Anos de Governos Pós-neoliberais no Brasil: Lula e Dilma. São Paulo e Rio de Janeiro: Boitempo Ed. e FLACSO, p. 135-144, 2013.

RAPLEY, T. "Interviews”. In: SEAL, O.; GOBO, G.; GUBRIEN, J.F.; SILVERMAN, D. Qualitative Research Practice. Londres, Thousand Oaks, Nova Délhi: SAGE Publications, p. 11-34, 2004.

RÊGO, W. L.; PINZANI, A. Vozes do Bolsa Família: autonomia, dinheiro e cidadania. São Paulo: Ed. UNESP, 2013a. 
RÊGO, W. L.; PINZANI, A. Liberdade, Dinheiro e Autonomia: o caso do Bolsa Família. Política \& Trabalho, n. 38, p. 21-42, abr. 2013b. Disponível em: < http://periodicos.ufpb. br/ojs2/index.php/politicaetrabalho/article/view/15029/9376>. Acesso em: 30 mai. 2013b.

SEN, A. "On economic inequality". In: FOSTER, James; SEN, Amartya. On economic inequality: expanded edition with a substantial annexe. Oxford: Clarendon Press, 1997.

SEN, A. Desenvolvimento como liberdade. São Paulo: Companhia das Letras, 2000.

SILVA, P. V. O PRONATEC-FIC no Rio Grande do Sul: quem é o seu participante? Dissertação (Mestrado). Universidade Federal do Rio Grande do Sul. Programa de PósGraduação em Educação. Porto Alegre: 2017, 107 f.

TELLES, Vera. Direitos Sociais: afinal do que se trata? $2^{\mathrm{a}}$ reimp. Belo Horizonte: Editora UFMG, 2006.

WORLD BANK. The World Bank Group. Address to the board of Governors, by Robert S. McNamara. Nairóbi, Quênia, 24 set. 1973. Disponível em: <http://siteresources. worldbank.org/EXTARCHIVES/Resources/Robert_McNamara_Address

_Nairobi_1973.pdf>. Acesso em: 08 jul. 2012.

WORLDBANK.WorldBankGroup.WorldDevelopmentReport.2001.Disponívelem:<http:/ / wwwwds.worldbank.org/external/default/WDSContentServer/WDSP/IB/2007/09/12/000 020953_20070912110712/Rendered/PDF/226840PORTUGUE1za20001200101PUBLIC1. pdf>. Acesso em: 19 fev. 2013.

VICCARI, E.; MARTINS, E. As políticas de assistência social e do trabalho: uma aproximação necessária no combate à miséria extrema no Brasil - a experiência do Rio Grande do Sul. In: BELLINI, M. I. B.; FALER, C. S. (org.). Intersetorialidade e políticas sociais: políticas sociais e diálogos. Porto Alegre: EDIPUCRS, 2014.

\section{NOTAS}

${ }^{1}$ O Sistema S é formado pelos Serviço Nacional de Aprendizagem Industrial (SENAI), Serviço Social da Indústria (SESI), Instituto Euvaldo Lodi (IEL), Serviço Nacional de Aprendizagem Comercial (SENAC), Serviço Social do Comércio (SESC), Serviço Nacional de Aprendizagem Rural (SENAR), Serviço Nacional de Aprendizagem em Transportes (SENAT), Serviço Social de Transportes (SEST), Serviço de Apoio às Pequenas e Médias Empresas (SEBRAE) e Serviço Nacional de Aprendizagem do Cooperativismo (SESCOOP), subordinados à Confederação Nacional das Indústrias (CNI).

${ }^{2}$ A teoria do capital humano assume que além dos ativos que produzem rendimentos, como máquinas e equipamentos, ações e imóveis, existem bens intangíveis cuja posse também gera divisas, principalmente a educação e a saúde. "Esses ativos são chamados de capital humano porque as pessoas não podem ser separadas de seus conhecimentos, habilidades, saúde e valores do mesmo modo como podem ser separadas de seus ativos financeiros e físicos". Assim, o capital humano refere-se à "educação formal, a um curso de informática, a gastos 
com cuidados médicos, palestras sobre as virtudes da pontualidade e da honestidade, pois eles melhoram a saúde e aumentam os ganhos dos indivíduos” (BECKER, 1993, p. 15).

${ }^{3}$ Para Putnam (2004) "o capital social se refere aos vínculos sociais e às normas de reciprocidade associadas". A premissa central da teoria do capital social é que os laços sociais possuem valor, decorrentes da confiança, reciprocidade, informação e cooperação. O capital social gera valor para as pessoas que estão ligadas umas às outras e, muitas vezes, para seus amigos e familiares.

Submetido: 01/06/2017

Aprovado: 09/01/2018

Contato:

Guilherme Dornelas Camara Av. Washington Luiz, 855, sala 445, Centro Histórico.

Porto Alegre|Rio Grande do Sul|Brasil. CEP 90.010-460 